\title{
Fear Appeals in Marketing Communications of Banks and Insurance Companies in the Continuum of Dramatic-Tragic Situations - The Semiotic Perspective
}

\author{
KAFTANDJIEV Christo ${ }^{15}$, SHUSTOVA Elena ${ }^{16}$
}

\begin{abstract}
The objective of the paper is to analyze from semiotic standpoint financial ads and other marketing communications, based on fear appeals, during an economic crisis.

A matrix which combines content and formal (sign) elements, forms the semiotic perspectives on which the article draws the conclusions. The content (pragmatic) elements are the fear appeals. The formal elements are the different signs and semantic concepts by which admen express fear appeals in their dramatic and tragic hypostases.

The analysed semiotic concepts used in advertising and other marketing communications are sign systems of body and face; stylistic figures (iconic comparison, iconic metaphors, iconic hyperbole, iconic opposition, iconic allusion); semantic concepts (redundancy and intertextuality) and, some syntactic concepts as context and Ambient.

One of the main conclusions is that advertising and other marketing communications of some world companies are so developed and sophisticated that, for a proper analysis of their campaigns, new semiotic concepts may have to be introduced.

The main paper's contribution to the existing semiotic literature is that any semiotic notion is not only an abstract phenomenon, but also a communicative approach or even communicative strategy. Communicators use these approaches actively and skilfully in the different communications, including advertising.
\end{abstract}

Keywords: financial crisis, fear appeal, semiotics, stylistic figure, iconic metaphor, intertextuality, Ambient

JEL: M30

UDC: 658.8.012.12:81'22

COBISS.SR-ID 265402124

\section{Goal of Article}

The goal of this article is to analyse the effectiveness of advertising and other marketing communications during a period of financial crisis and, furthermore, to examine the main ad appeals and communication approaches actualized in these ads. The appropriate ad appeals help to sell effectively different financial products during the hard times of a financial crisis.

\footnotetext{
${ }^{15}$ KazHLIU University, Kazakhstan; Sofia University, Bulgaria

${ }^{16}$ KazHLIU University, Kazkhstan
} 


\section{Structure of Article}

According to the goal described above, this article aims at an analysis of:

- ad appeals;

- psychological schools and the system of ad appeals;

- "The Maslow Pyramid" and marketing communications;

- fear appeals in normal situations;

- fear appeals during a crisis situation;

- appeals of destruction and (cruel) death.

\section{Value of Article for Readers}

This article can be of some help for specialists in the field of financial advertising and marketing for two reasons:

The first is that any linguistic and semiotic concept is also a communicative approach or even a communicative strategy. For example, one of the most successful global advertising campaigns is that of Vodka Absolut. The whole campaign is done on the basis of visual (iconic) metaphors, supported by unified module.

Several important communicative approaches, based on semiotics and the theory of archetypes, are analysed in this article.

The second reason is that the financial crisis seems to be permanent. In an article of the newspaper "Die Welt" of 21 November, 2017, its authors, Holger Zschäpitz and Anja Ettel, interviewed 18 Nobel laureates in economics about the prospects of a new financial crisis.

According to these scientists, yet another crisis is quite possible. This is the opinion of Bengt Holmström, who received the Nobel Prize in 2016; of Edward Prescott, Nobel Prize laureate for 2004; of Eric Maskin-Nobel laureate for 2007; of Daniel McFadden - Nobel laureate for 2000, etc. Of all scientists, only Vernon Smith (Nobel laureate for 2002) is optimistic about the future of the Euro.

Because of this, ads and other marketing communications of financial services will continue, now and in the future, to make use of fear appeals.

\section{Acknowledgement to Admen whose Ads are used in the Article}

Some of the world's best ads and other marketing communications are used in this article.

They are excellent examples of the high communicative abilities and creativity of their innovative authors. The ads are from the site: http://adsoftheworld.com/ which is one of the leading international online mediums in advertising. The site is also very useful for specialists who work in the field of advertising and other marketing communications.

The authors of this article express their deep gratitude to the creators of the ads quoted here, as well as to the specialists who set up and maintain so well the "ads of the world" site.

\section{Literature Review}

The following topics are discussed in this article: psychology and advertising, ad appeals; psychoanalysis and advertising; Abraham Maslow and advertising; fear appeals; financial crisis; semiotics - iconic metaphors, intertextuality, semantic field; theory of archetypes; eschatological myths 


\section{Psychology and Advertising, Ad Appeals}

Advertising psychology and ad appeals are of key significance for the efficient impact of advertising on consumer groups such as banks and insurances, and therefore they are the object of many research studies. One author thoroughly explores ad appeals which appeal to consumers both on the conscious and the subconscious level. (Gill, 2013) Another book analyses consumer psychology, ad appeals and their impacts on the acquisition and processing of ads, ad influence on consumers' memory in the formation of attitudes towards the advertised products; persuasion and attitude change; and, last but not least, how consumer psychology and ad appeals control buying behaviour. (Fennis and Stroebe, 2015)

The subconscious (archetype appeals) and the psychology of emotional influence in advertising are studied in Robert Heath's book. He provides an in-depth analysis of such important topics as attention memory; emotion and consciousness; the subconscious and communication; emotions and attention, the Subconscious Seduction Model (SSM), etc. (Heath, 2015)

The "Handbook of Consumer Psychology" is one of the most important scientific research studies on consumer psychology and ad appeals. Here are analysed such phenomena as knowledge accessibility; consumer memory; consumer learning; sensory factors in consumer behaviour; motivation and consumer decisions; persuasion and social influence; hedonism and consumer behaviour, etc. (Haugtvedt et al., 2012) Valuable research on ad appeals of humour is done in scientific article by Crawford and Gregory. Its goals are to analyse the scientific literature on humour in cross-cultural advertising and to produce relevant research taxonomy on its basis. (Crawford and Gregory, 2015) The same is more or less true with regard to fear appeals.

The significance and effectiveness of nature scenery in various ads are analysed in an article written from three viewpoints - ecological, psychology of consumers, and semiotics. One of the main findings is that consumers prefer nature scenes with biospheric contents to pictures of urban environments or desert settings. (Hartmann Patrick, Vanessa ApaolazaIbáñez, 2010). This article confirms the fact that nature is also an index sign system, by means of which communicators express different meanings. Some cruel nature sceneries are analysed in this article.

\section{Psychoanalysis and Advertising}

Psychoanalysis is one of the main psychological schools which many scholars turn to in order to explain consumer behaviour. One of Freud's most important postulates is about the dark side of the human psyche. Fear appeals in their dramatic and tragic hypostasis are part of this theory.

Some scientific books and articles analyse the subconscious from the point-of-view of advertising and marketing. The basic idea is that advertising uses the postulate of the subconscious to give the consumers exactly what they want.

Advertising is very successful in this respect. (Haineault and Roy, 1993) Forest's study is based on the hypothesis that "ads are structured like dreams".

The author examines what hidden meanings ads can carry. Archetypal appeals and especially those which epitomize fear, drama and tragedy illustrate well this theory. (Forest, 2016) Intersection of brand positioning, semiotics of gender, and consumer desire in advertising discourse are the topics of another scientific article. Here the author focuses on the dialectical implications of the spectator/consumer's psychic drives in visual ad semiotics. (Oswald, 2010) 


\section{Abraham Maslow and Advertising}

Fear appeals must also be examined from the point-of-view of Maslow's "pyramid of needs". The most important reason for this is that fear appeals constitute the second level in this model, which has proved to be so valuable for psychology and marketing. Maslow's hierarchy of needs is usually interpreted as a universal model, but some scientists disagree with this by emphasizing the need for an intercultural perspective. One study stresses the importance of Maslow's model for human civilization, but also the need to modify it, because of the significant differences between cultures - Arabic and Chinese culture, for example. The reason for this is that the "pyramid model" was created on the basis of Western culture values.

For example, the upper pyramid's levels for some Asian cultures are "status", "admiration" and "belonging". The same levels of needs in some Arabic cultures, however, are "respect", "social needs" and "self-improvement". (Rakowski, 2008)

Other research studies arrive at similar conclusions. (Mueller, 2011) Individualistic western cultures differ to a large degree from collectivistic-oriented eastern cultures (De Mooij, 2014). Even in relatively close cultures phenomena, connected with fear appeals, can vary to some extent. In one article Maslow's motivation theory is explored within the framework of an economic analysis. The authors set up a new model to explain how changing levels of economic income and certain forms of wealth influence the desired content of consumer bundle. (Seeley, 1992) In one book about corporate security and commercial success is analysed the marketing potential of security and its importance for the behaviour of different consumer groups. Cabric examines the security phenomenon (the second level of the Maslow pyramid) in relation to the four main parts of marketing-commodity, communications, logistics and cost. (Cabric, 2017)

\section{Fear Appeals}

Fear appeals are analysed in a number of research studies. In one article, the authors arrive at the conclusion that highly intensive fear appeals are more convincing than those with lower intensity. (Witte and Allen, 2000) In another study the authors examined the existing scientific literature regarding fear appeals used in advertising. According to the authors, the problem is that there is no generally accepted theory of fear appeals. Some of the reasons for this are related to the individual and cultural differences among various consumer groups. (LaTour and Pitts, 1989)

LaTour and Shaker conclude that the theories on advertising with regard to fear appeals are unsatisfactory. (LaTour and Shaker, 1989) Other research studies agree with that. The reason for this is that studies on fear appeals are mainly done with students. This is not quite correct from the standpoint of validity. More reliable research about fear appeals does not show any particular effectiveness of fear appeals in social marketing campaigns. Because of this, positive appeal can also be used - such as humour, postmodern irony, good behaviour, etc. (Hastings, Stead and Webb, 2004) One article explores the effectiveness of fear appeals in road safety advertising. The authors conclude that the various studies on these topics are inconsistent. According to the authors fear appeals in ads are efficient when they succeed in attracting the consumers' attention. Such ads do not impress young men, however when admen showed physical harm to them - injuries, etc. (Lewis, Watson, Tay and White, 2007)

\section{Financial Crisis}

Oldani, Kirton and Savona analyse financial crises and their impacts. Their study tries to give answers to questions with regard to problems concerning international cooperation, coordination and institutional changes in global economic governance, and to identify ways of reforming the failing financial system. (Oldani, Kirton and Savona (Eds.), 2013) The present global financial crisis and its economic and other consequences are examined in another book, 
which asserts that the collapse of banks is proof of the systemic crisis of the capitalist system. (Fadda and Tridico (Eds.), 2013)

The regulatory mechanisms (Basel Accords) in relation to capital adequacy of banks are the topics of Friedman's and Kraus' study. According to them, these mechanisms are the immediate cause of the 2007-2008 financial crisis. (Friedman and Kraus, 2011) Ciro's study examines different aspects of the catastrophic international financial crisis that occurred between 2007 and 2008. (Ciro, 2013)

\section{Semiotics - Iconic Metaphors, Intertextuality, Semantic Field, etc.}

One of the basic semantic concepts with regard to advertising creativity is metaphor. George Lakoff's and Mark Johnson's book "Metaphors we Live by" is one of the most important studies on this topic. (Lakoff and Johnson, 1980).

Evripides Zantides examines visual metaphors in advertising with regard to intertextual semiosis and advertising. One of the most important conclusions the author arrives at is about the visual metaphors and how they are used to attract the viewers' attention as well as to enhance the ads' persuasive values.

Intertexuality is applied quite regularly in ads, and admen get their ideas from paintings, films, novels, etc. (Zantides, 2016)

Quite important in this respect is also an article in which verbo-visual rhetorical figures (metaphors, metonymies, hyperbole, litotes, apheresis, apocope, ellipsis, zeugma, asyndeton, neologism, paronomasia, pareikonopoeia, adjunction, etc.), that appear in hundreds of commercials, are analysed from the standpoint of sequences. Rhetorical iconic and mixed figures are the core of ad creativity. (Rossolatos, 2014)

The same author explores important aspects related to the use of rhetorical (stylistic) and visual (iconic) figures such as metaphors and metonymies in another study. He raises important questions concerning the problem, if visual is isomorphic to verbal. Furthermore, he analyses in depth, how metaphors, metonymies and the other stylistic figures interact in multimodal ad texts. (Rossolatos, 2013)

The concept of intertextuality is in the centre of Allen's study. He explores different theories - structuralism, post-structuralism, deconstruction, post colonialism, Marxism, feminism, etc. He also quotes the views of some of the world-wide most renowned linguists and semioticians, e. g. Saussure, Bakhtin, Kristeva, Barthes, Bloom, etc. (Allen, 2011)

The different theories about intertexts (allusion and intertexts, chronotope and intertext), etc. are studied in depth in another book. (Clayton and Rothstein (Eds.), 1991). Intertextuality and ontology; autobiography as intertext; intertext, irony and politics of reading; intertextual relations; intertextuality in cinema, etc., are the subject of analysis by various authors, whose theories are presented in the book "Theories and Practices". (Worton and Still (Eds.), 1991)

\section{Theory of Archetypes}

The theory of archetypes gives important ideas of the most important mental structures that act on a subconscious level, such as left/right; up/down; symmetry/asymmetry, etc., which are the basis of persuasive and manipulative communications. The American scientist Vance Packard (Packard, 1964) analysed some of these archetypes in marketing communications. Some of his ideas are used in this article.

\section{Eschatological Myths}

One important book about myths is by Douglas Allen. The seventh chapter of his book is about the structure of myths; sacred and symbolic; structure and functions of myths; cosmogonic myths; myths of origins; eschatological myths and mythological renewal. (Allen, 2002) 
The best book on mythological theory is "The Poetics of Myth" by Eleazar Meletinsky. He analyses the general characteristics of myths, mythical time, ancestors and heroes, chaos and creation of the universe, seasonal myths, the end of the universe, heroic myths, etc. We consider Meletinsky's book to be very important because it examines in detail eschatological myths (the myths of the last days.) These myths are activated in times of human crises - wars, natural disasters, etc. and also financial crises. (Meletinsky, 2014)

\section{Main Text}

\section{Ad Appeals}

Ad appeal (from Engl. - "to attract") is the psychological motif (drive) that "pulls" the customers to the advertised product/service.

The classification of ad appeals can be done on the basis of different variables.

- One of the best approaches is based on structuralism - i.e. organizing the appeals in the form of oppositions:

- $\quad$ appeals working on the conscious/subconscious level;

- rational/emotional appeals;

- $\quad$ appeals, based on national values/appeals based on global values;

- appeals on basic physiological needs/appeals on superior psychological values (selfimprovement, sacrifice, etc.);

- appeals of power (might)/appeals of obedience;

- appeals in the continuum of serious attitude - humorist interpretations, and so on.

\section{Psychological Schools and the System of Ad Appeals}

\section{Psychoanalysis and Marketing Communications}

Obviously, appeal is a psychological and somewhat sociological phenomenon.

It determines our thinking, mainly because of our mythological prejudices.

Psychoanalysis is the theory that explains very well the psychology of customers in the system of marketing communications, with their desire for power and pleasure. Especially valuable are the postulates for latent and permanent evil, pessimism and mythological (not rational) thinking of mankind.

In this respect, psychoanalysis is very close to Kafka's, Dostoevsky's and Joyce's novels.

This way we can understand well some part of post-modern trends in advertising that have evolved over the past thirty years. Pessimistic appeals, lack of belief in human progress, and so on, are dominant in postmodern marketing communications.

Our mythological thinking nourishes and maintains, on the subconscious level, these specific appeals. One of their main constituents is eschatological myths - those about the destruction, death and extermination of mankind. World and global advertising campaigns e.g. by Smirnoff Vodka; Diesel jeans, Benetton clothes and others show evil and destruction - even at times of economic prosperity.

In one of Smirnoff's ads stone heads swallow innocent pigeons (Fig. 1) and sinister surgeon-cannibals, instead of operating, are prepared to feast with their patients (Fig. 2). 


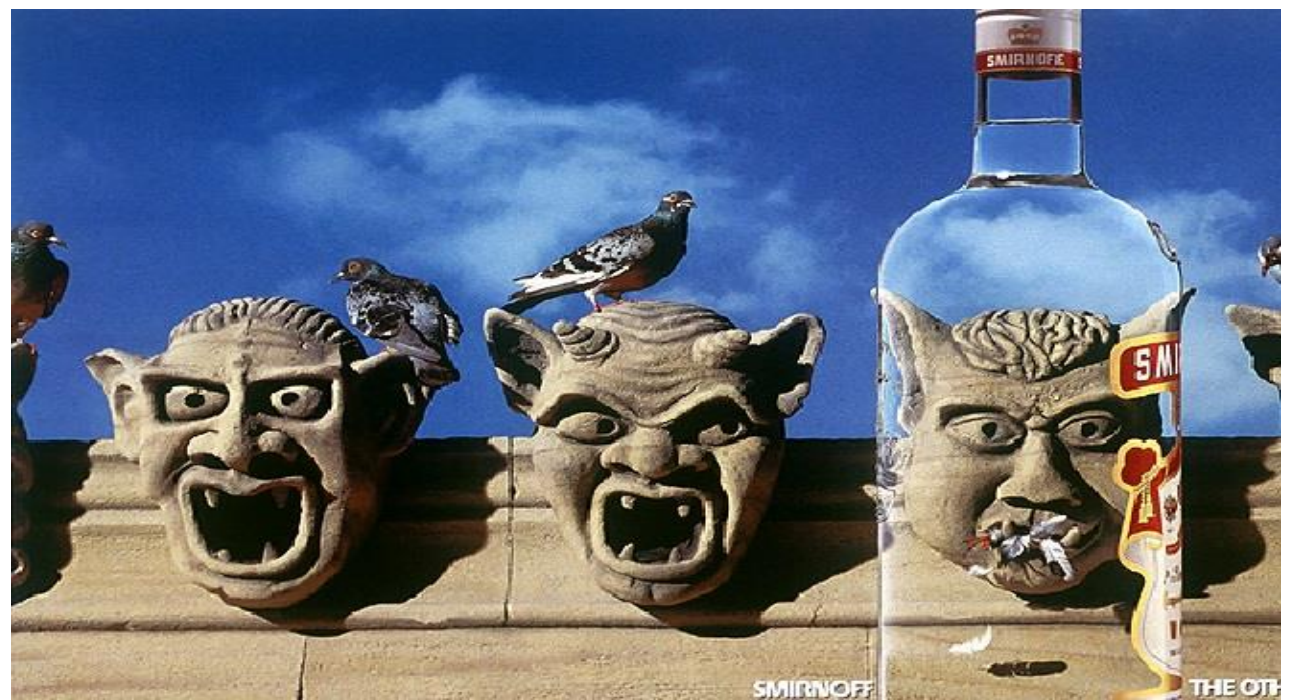

Fig. 1. Courtesy

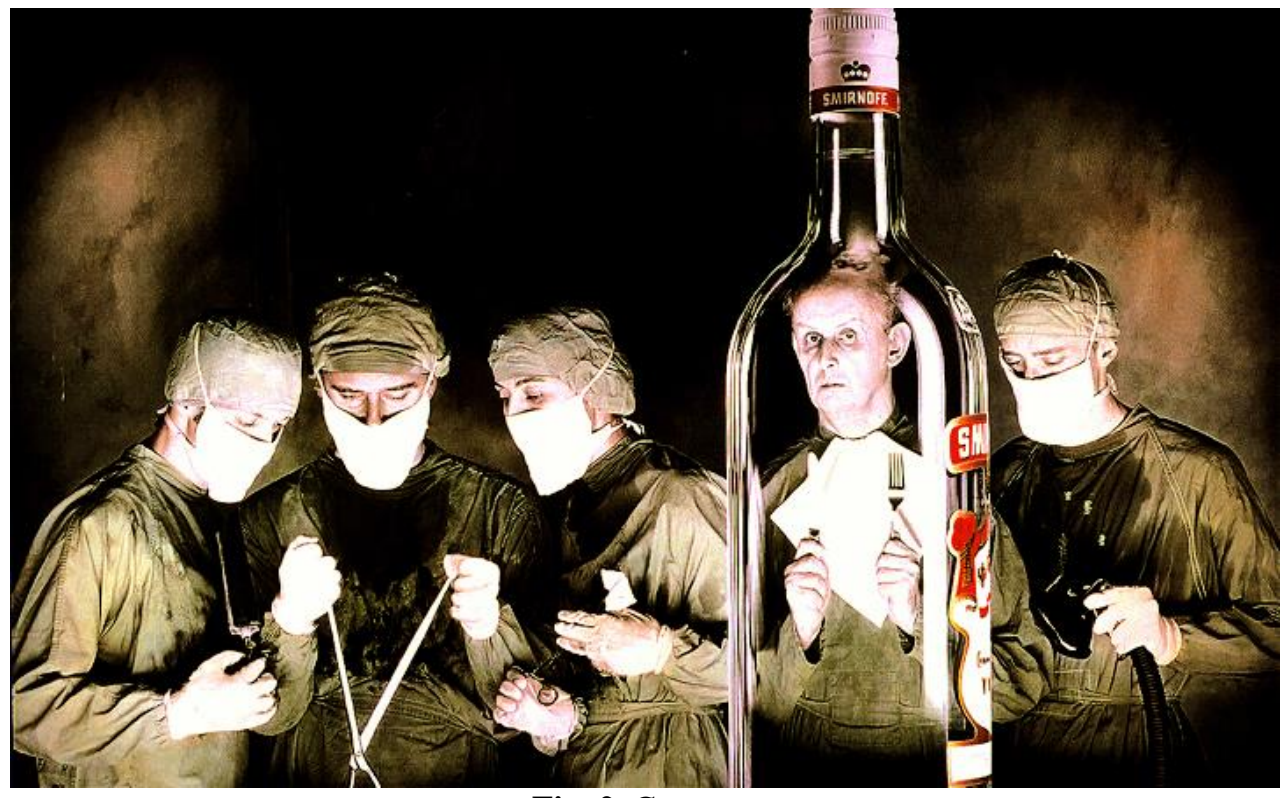

Fig. 2. Courtesy

Diesel ads are created in a more humorous but no less sinister way. A sadistic dentist is terrifying a little girl by torturing her with fearsome metal instruments (Figure 3). 


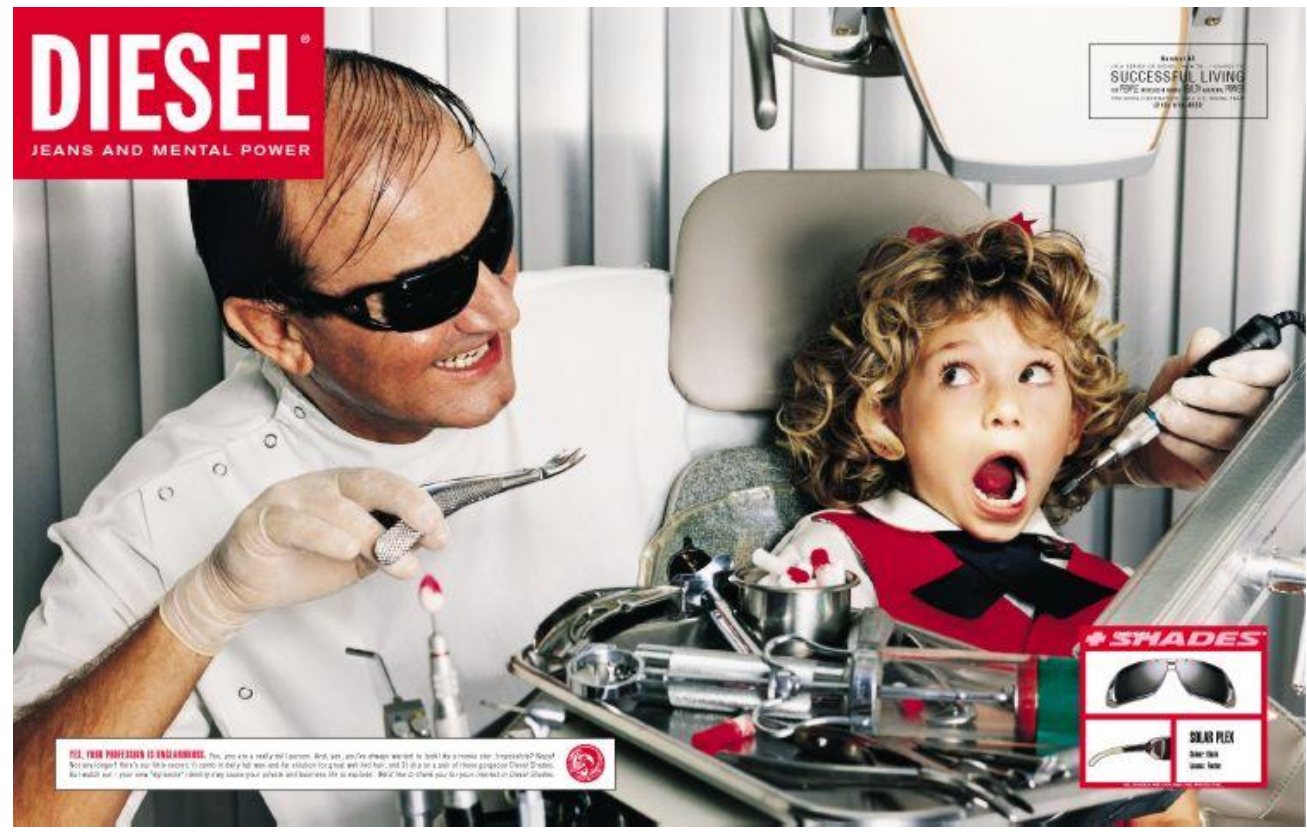

Fig. 3. Courtesy

In another ad beautiful Circe has transformed Ulysses' sailors into pigs. The happy pigsailors will soon start to devour one of their baked comrades. (Figure 4).

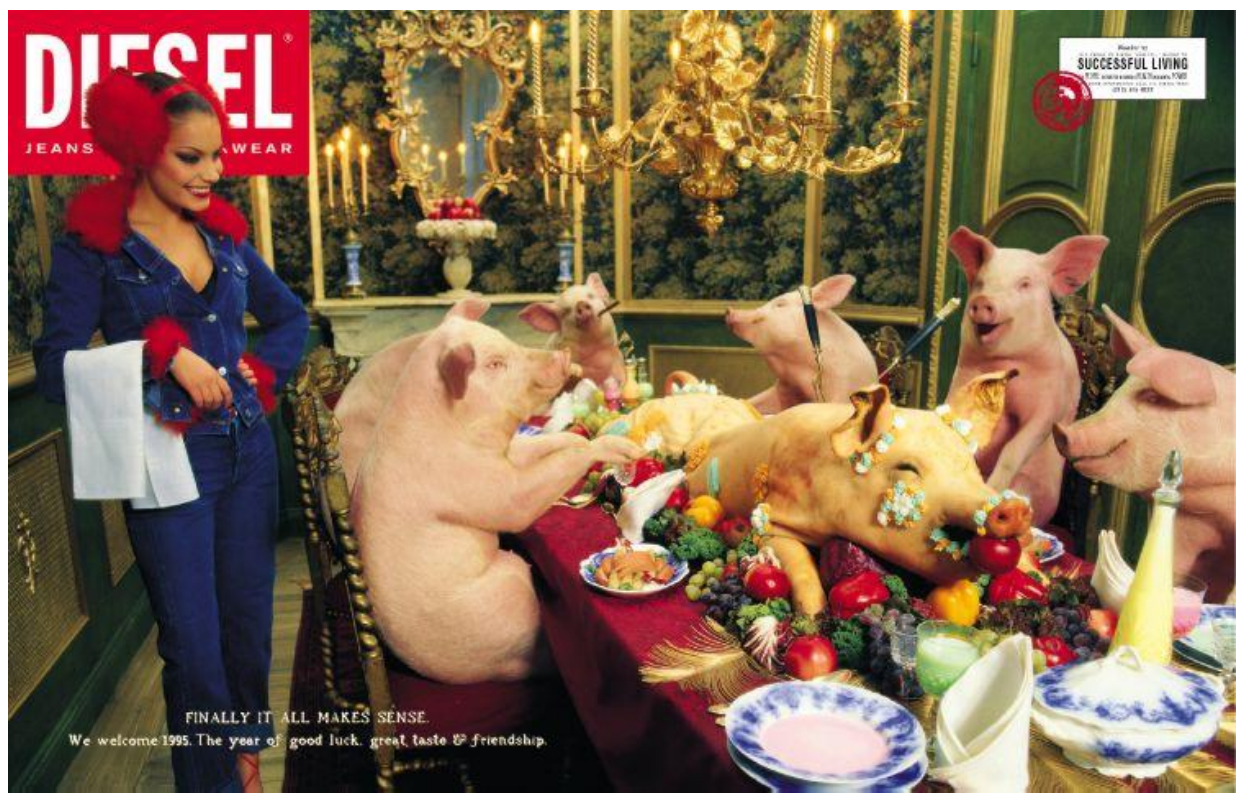

Fig. 4. Courtesy

There is not the slightest sign of humour appeals in Benetton's ads, which is typical of the ads of the other two companies. One Benetton ads shows the blood-stained clothes of a killed soldier (Fig. 5), another - a human bone in close-up image. (Fig. 6) 


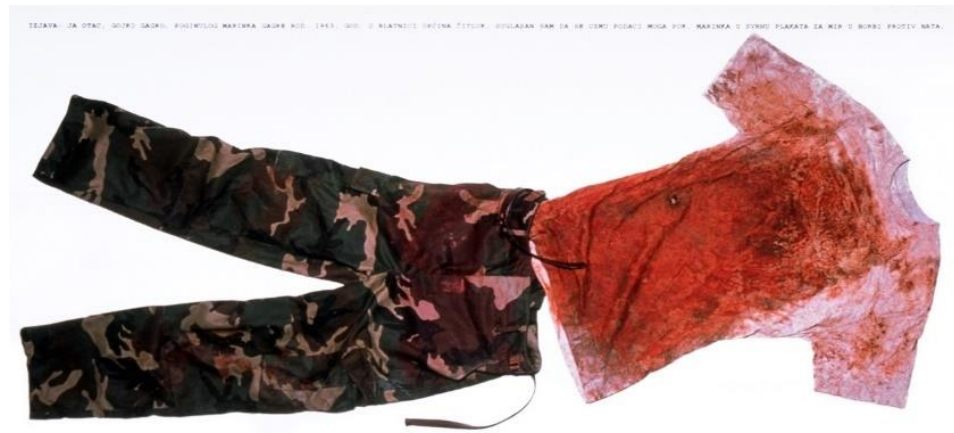

\section{UNITED COLORS
OF BENETTON.}

Fig. 5. Courtesy

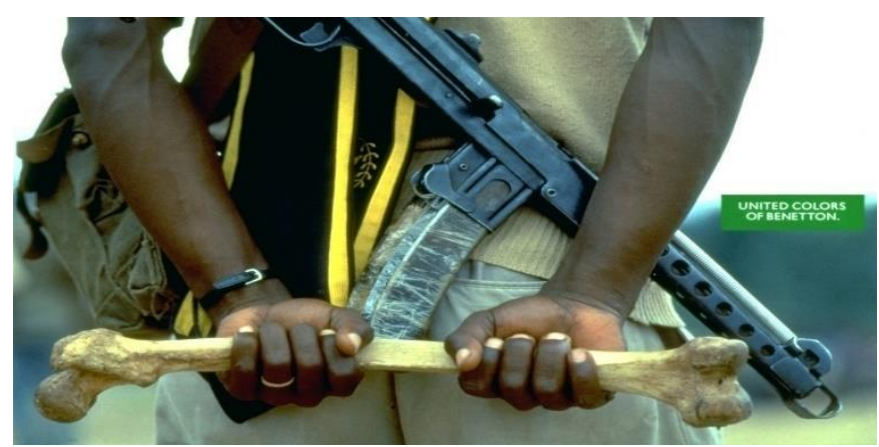

Fig. 6. Courtesy

\section{“The Maslow Pyramid" and Marketing Communications}

One of the most commonly used psychological models in advertising is that created by Maslow. According to it, human needs are arranged in a hierarchical pyramid order. The physiological needs-sleep, food, and so on, are at the lowest level. The second level expresses the need for protection. The needs through which we define ourselves as social and ethical beings - the needs for displaying a friendly attitude towards our fellow-men, for belonging to a group, helping others, philanthropy, self-sacrifice, etc. form the upper pyramid levels.

We cannot move to the highest levels, if we haven't satisfied the needs of the lower ones.

The modern world is in a permanent political and financial crisis. These are tough, dramatic times, but they cannot be compared with war times. War is tragic, but not dramatic - when people are raped, when they die of hunger and cold, when they are killed, etc.

The difference between drama and tragedy is explained in detail by the theory of literature. Characteristic of the dramatic situation is insignificant or significant trouble, but tragedy means death.

It is quite natural, however, that advertising and other communications on purpose use fear appeal. The media exaggerate by default, and advertising does the same. That is why mass media and advertising can be defined as typical hyperbolic communications. In ads we find not only dramatic appeals but also appeals, by which admen (more politically correct: adpersons, because a lot of women work in ad agencies) interpret reality in a tragic way - like in ancient Greek tragedy. 
One of the best classifications of ad appeals in this respect is the continuum of fear appeals (crises, dramatic appeals) and catastrophic appeals (disastrous, tragic appeals).

\section{Fear Appeals in Everyday Situations}

Admen often use fear appeals in marketing communications. The obvious reason is that people are constantly under stress. We overcome this unpleasant (awful) feeling by buying relevant goods and services - such as insurances, weapons, sedatives, exotic travels, food, drinks, etc.

Adpersons often use these appeals in marketing communications in crisis situations political, military, financial, etc. There are numerous examples of communicative ad approaches in critical situations.

For example, pigeon-hooligans are about to rip up five pairs of jeans, which are not insured (Fig. 7). Insurance is a fairly abstract concept. This is why the creative admen replaced it entirely (i.e. metonymiezed it) with the help of 11 red pegs. These simple tools firmly protect the jeans from being destroyed by the annoying pigeons. The communicative approach here (from the standpoint of semiotics) is that of iconic metonymy. The abstract concept of danger has been replaced entirely by the concrete images of nasty pigeons.

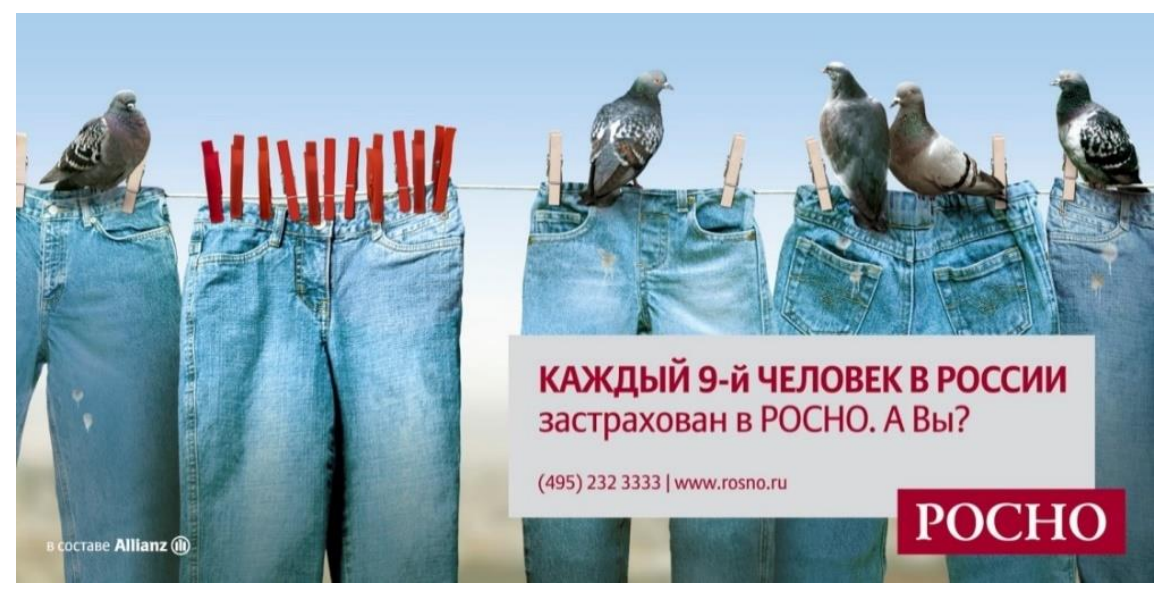

Fig. 7. Courtesy

An aggressive thief is stealing a TV set in an insurance ad (Fig. 8). Here the admen use the vestem sign systems (black clothes) to express criminal behaviour.

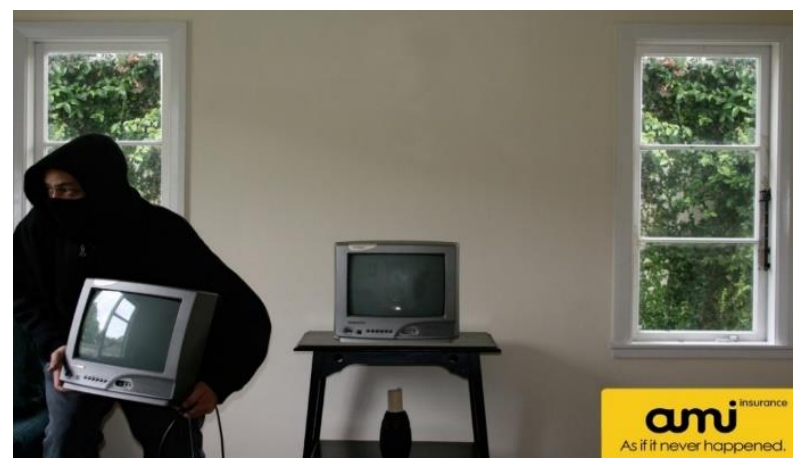

Fig. 8. Courtesy 
The ad specialists in a series of three ads for the Swedish financial newspaper Dagens Industri (Fig. 9a, 9b, 9c) changed the social roles - businessmen clean up shoes and pools and prepare a hot dog. The reason for having lost their attractive social role is that they did not read the newspaper at the dangerous times of the financial crisis.

The communicative approach here, from the semiotic standpoint, is that of iconic contrast (opposition, counterpoint). Social phenomena (low social status) are opposed by the sign systems of clothes - which signify a high social position.
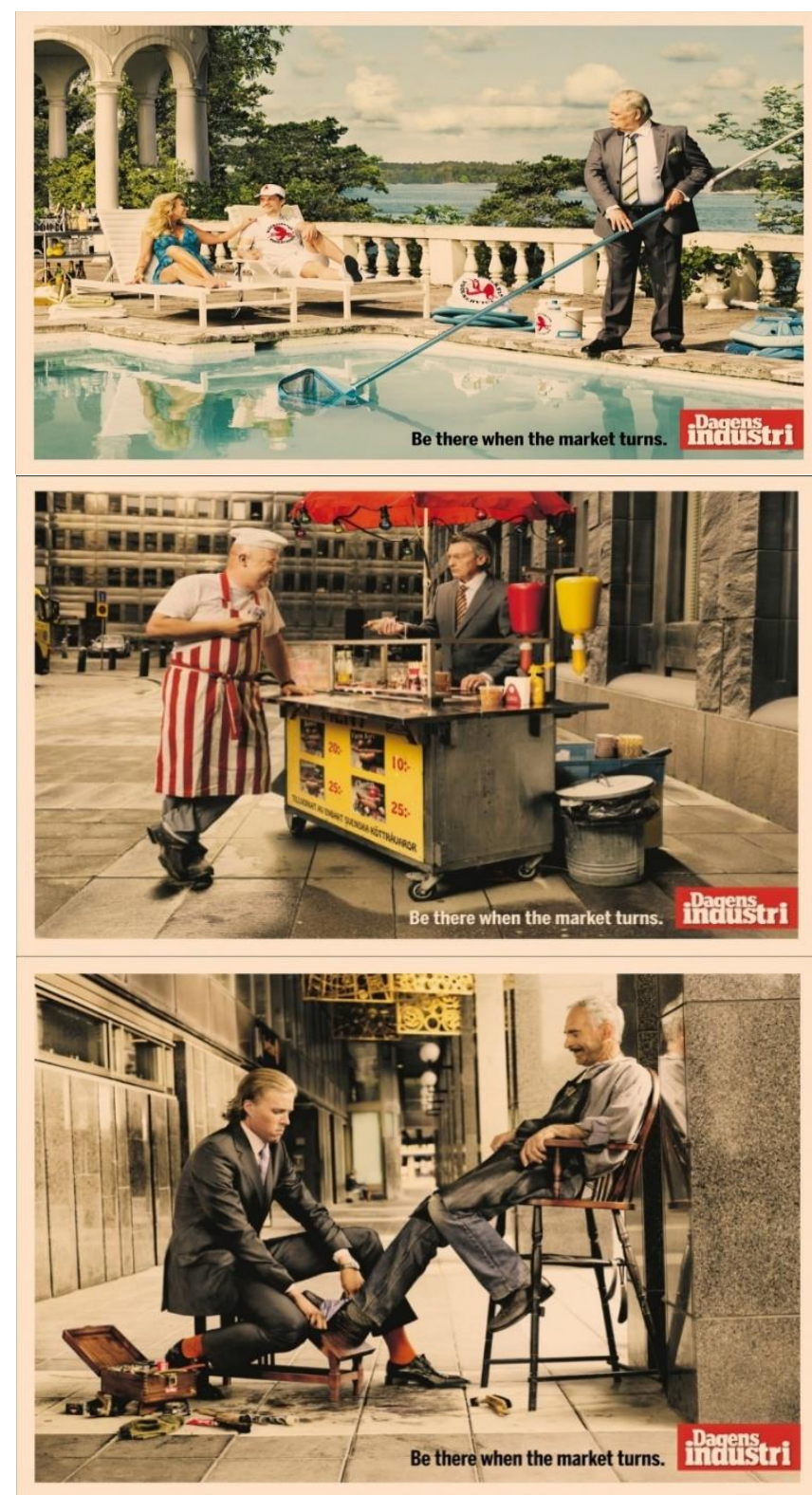

Fig. 9a, 9b, 9c. Courtesy 
Job agency shows us how bad it is to work in the wrong job (Fig. 10a, 10b, 10c). Here, the admen use a creative visual approach - three unfortunate workers are stuck in very narrow machinery spaces. The disaster is awful - they are already exhausted and mad because of the heavy, dirty and humiliating work in their hot, dirty and claustrophobic cages.

Here the creative specialists actualize two stylistic figures at the same time:

- One is iconic hyperbola - the awfulness of the cramped spaces is maximalized by revealing excessively their disgusting characteristics.

- The second is iconic opposition. The archetype appeal of paradise (pleasure) is opposed to the ultimate misery of hell - the happy people are having fun while the unfortunate slaves are working in disgusting and miserable hell-like conditions.

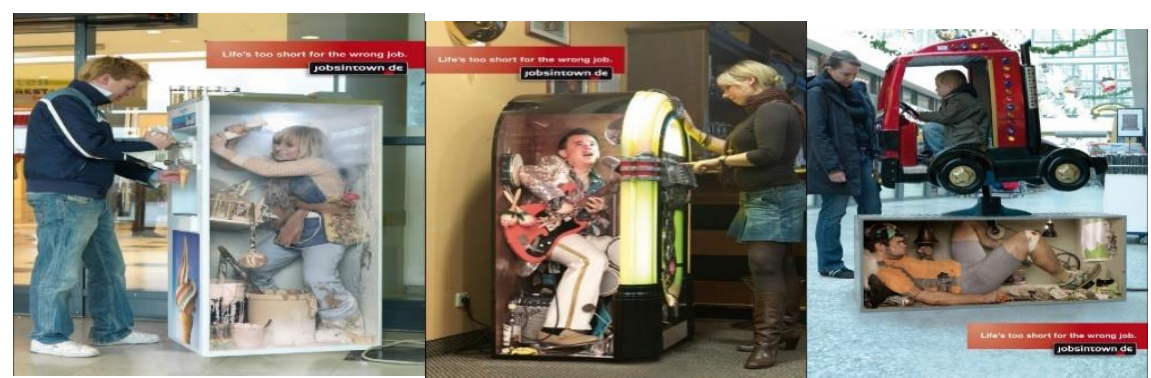

Fig. 10a, 10b, 10c. Courtesy

The archetype opposition "order/chaos" is one of the most important used in ads, and it conveys directly the idea of paradise and hell, alongside with the idea of eschatological myths.

In two ads (Fig. 11aq 11b) a bank makes use of the idea of hell - grandma and grandfather are on the brink of having a nervous breakdown. They are in peaceful and clean paradise, which is being invaded by their grandchildren. The little devils bring with them, like Huns, dirty, aggressive, noisy and chaotic hell. The only escape for the grandparents is to go on a trip, financed by a credit loan - from the advertised bank, of course.

Admen once again use iconic opposition as a communicative approach. By means of this they integrate (in one and the same text) parts of the semantic fields of hell and paradise - thus highlighting the pensioners' suffering. (Of course, everything is exactly the opposite from their grandchildren's point-of-view.)

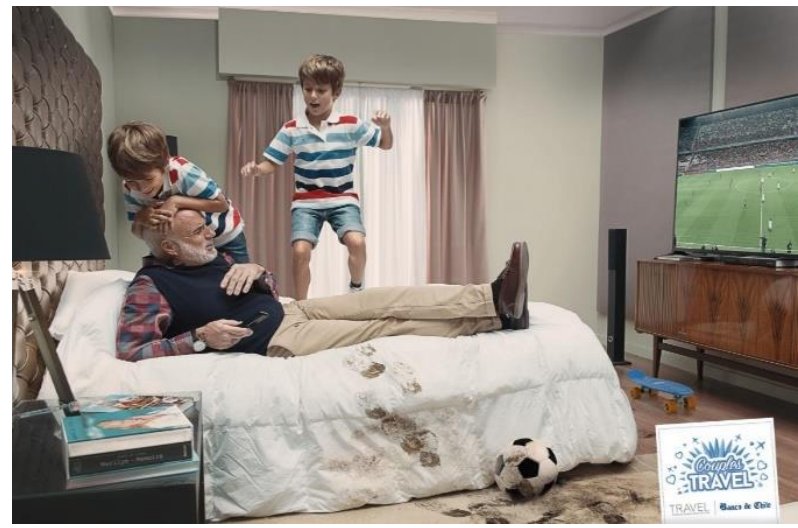




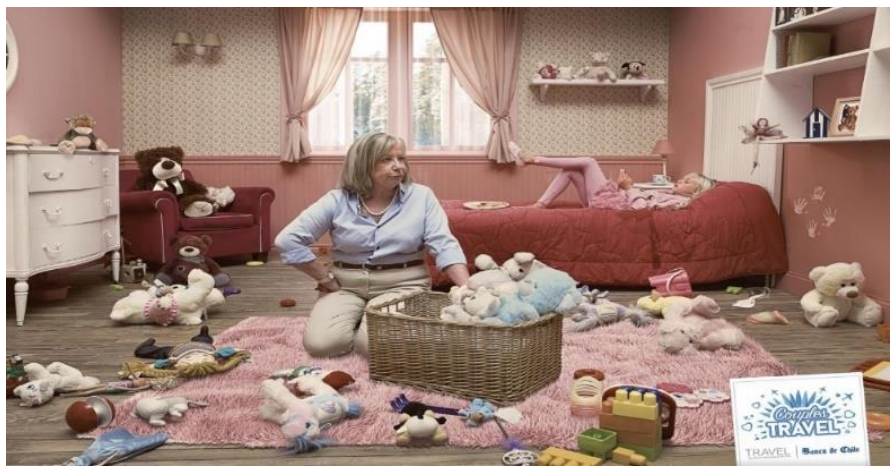

Fig. 11a, 11b. Courtesy

In an ad of a company insuring valuable paintings admen dramatised the topos with the help of fear appeals. For this purpose, they used Van Gogh's famous painting "Bedroom in Arles". In Van-Gogh-style the art director shows a flooded room, and this way the southern French paradise is transformed into hell. The communicative approach here is editing, and not intertextuality (allusion), because the painting has only been slightly changed.

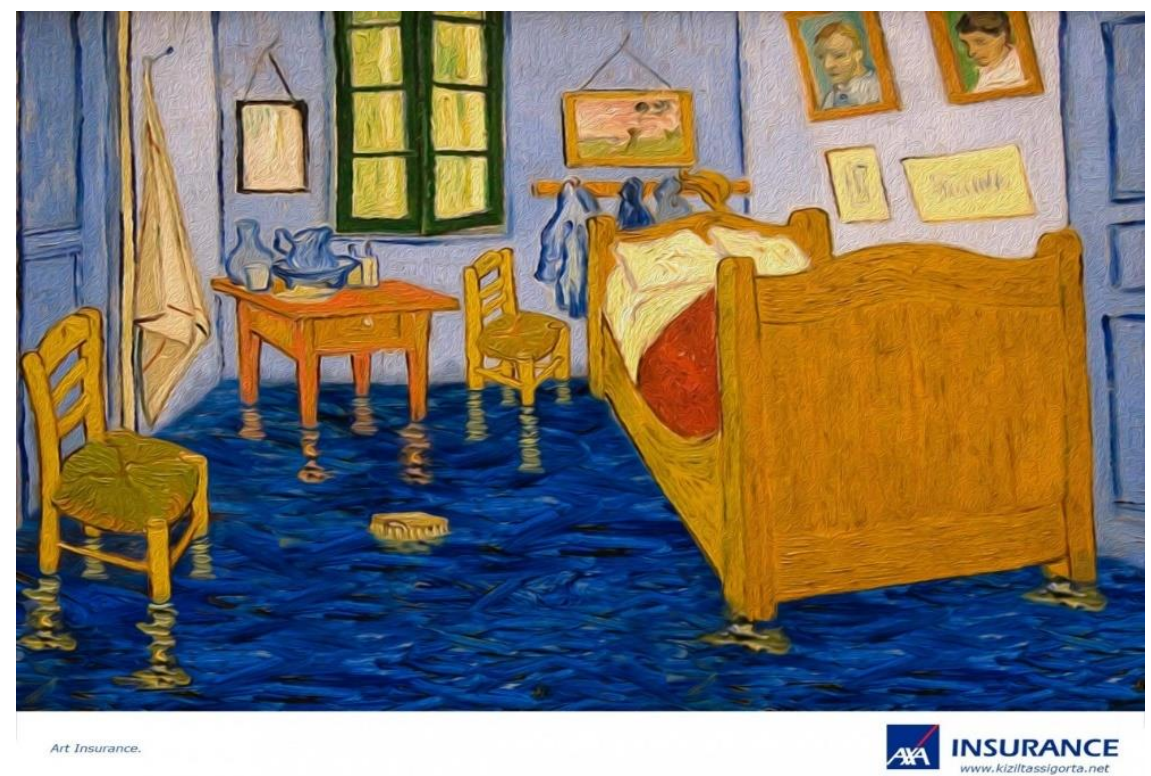

Fig. 12. Courtesy

In the three ads for an insurance company shown in Fig. $13 \mathrm{a}, 13 \mathrm{~b}$ and $13 \mathrm{c}$, the art director actualized a rare typographic metaphor done by the simultaneous use of the internal and the marginal space of the magazine page. The safe space, in this case, is the internal one, whereas the outer (the marginal) space is associated with danger. These spaces with the help of typography represent this archetype opposition in a very original (creative) way.

Parts of the car, the hand and the house are beyond of the safe place (the typographic space) into the dangerous outside (the marginal space). This is the reason why the car, the hand and the house are split up into two parts. 
It is not by chance that the ad title says "It's rough out there." The juxtaposition between internal and external space expresses, in the best possible way, the ideas of protection and of peril. The outer space represents the idea of danger, and everything there suffers.
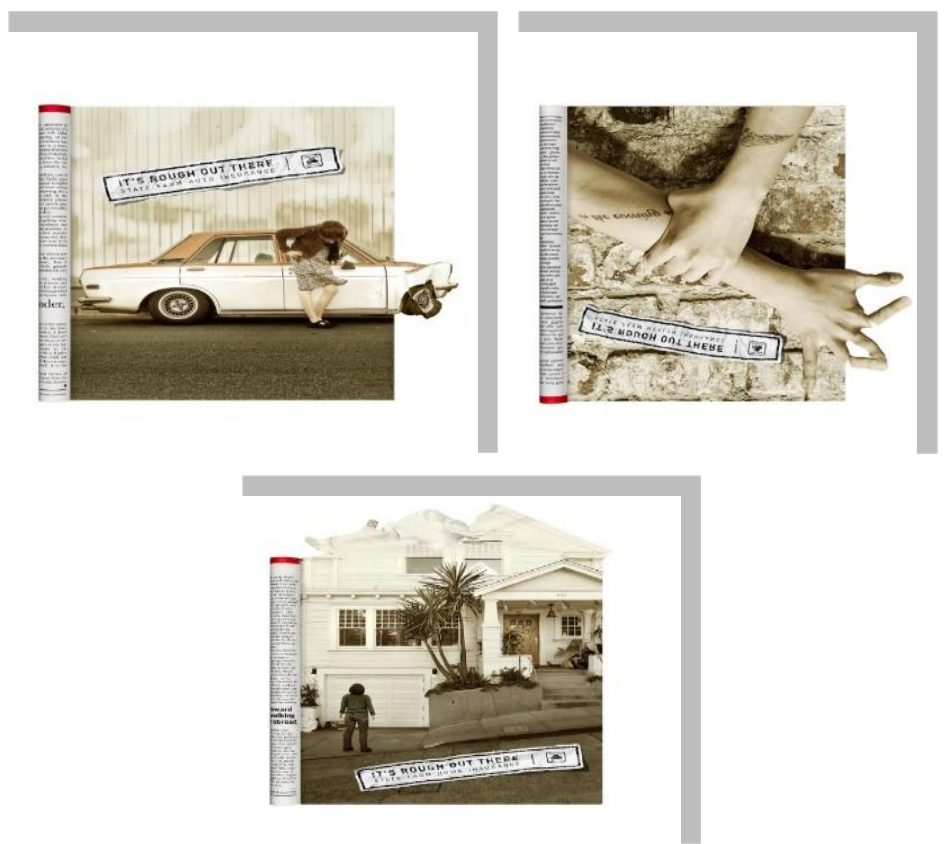

Fig. 13a, 13b, 13c. Courtesy

The headline of the advertisement on a billboard, onto which a Russian bank placed its message, says that crisis without panic is losing its beauty (Fig. 14).

This financial institution offers safe deposits. The easiness (calmness) expressed in the Russian ad is in sharp contrast with the panic and the fear appeals of Western ads.

This is perfectly understandable, but only, if we know about Russian history and Russian mentality. The Russian society has always been in a permanent crisis - since the beginning of its history, passing through Ivan Grozny, Peter the Great, pogroms, the Bolshevik revolution, golodomor, perestroika, and so on. Today's financial crisis is hardly likely to scare off a tough Russian.

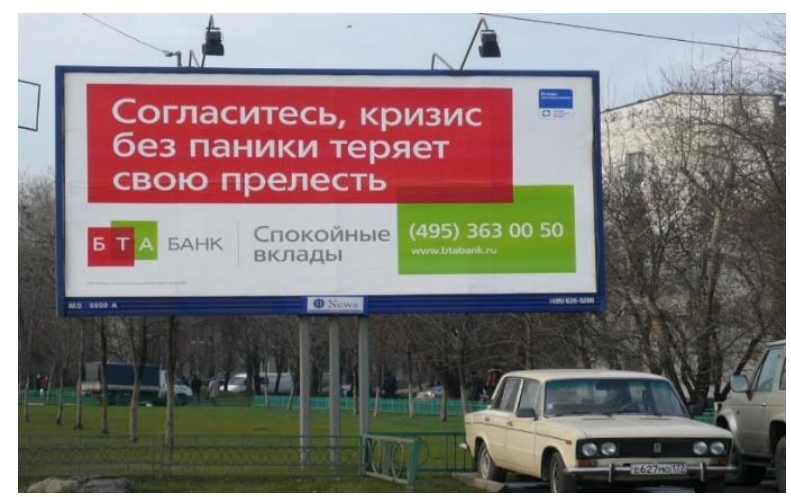

Fig. 14. Courtesy 
In the marketing communications for this bank admen used also Ambient advertising. It is one of the most efficient context ad communicative approaches.

"Ambient" in ad slang means that we put the ad into a particular context in order to enhance the meaning of the message to be conveyed. Ambient uses the potential of the surrounding environment, which can carry meanings as the other signs.

This is one of the most convincing examples that prove how valuable semiotics is with regard to communication.

The surrounding environment is boundless, and so are many index signs - as long as we can see and use their sign potential. Because of this every adperson is a semiotician on an intuitive or a conscious level, and Ambient is one of the most advanced and valuable advertising genres.

The Canadians used the context "closeness to US" in a travel insurance and ambient ad (Fig. 15). The reason is that American hospitals are quite expensive for Canadians who have no travel insurance. The insurance company placed three billboards along the highway, leading to the border - in order to influence Canadians who are travelling to the USA.

The billboards look just the same as the highway signs and even the reflective surfaces are identical. They remind travellers of the financial dangers (high charges) of US medical care.

This way the insurance company hints at the last chance to get coverage before it is too late.

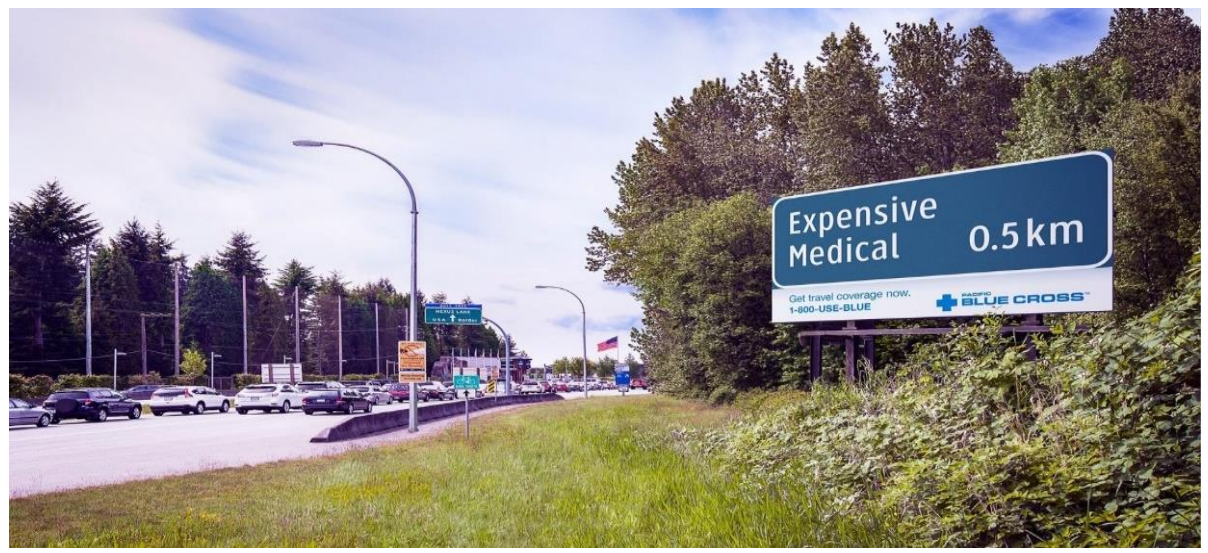

Fig. 15. Courtesy

Creative approach based on context is used in the DAS insurance company billboard (Fig. 16).

Here the highly talented admen use very rare communicative approach. The main reason is that the ultimate goal of advertising is always to create a feeling of happiness and might, but in this case, it is vice versa.

The ad title "The answer to all the things you did not ask for" explains this "contradiction".

The adpersons (in order to illustrate it) positioned different billboards in place, where they definitely create trouble - for example right in front of a parked car. This way the billboards simply blocks the car. 


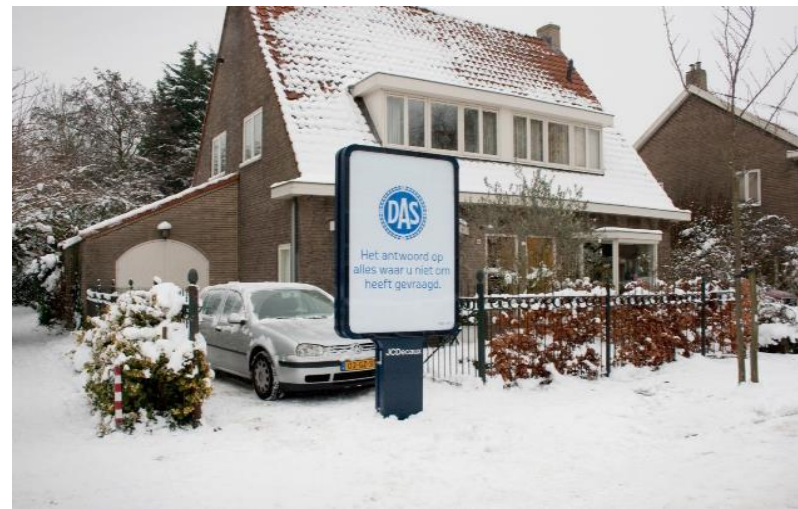

Fig. 16. Courtesy

Other art directors also make very creative (from a semiotic standpoint) use of the material from which a billboard is made (Fig. 17a, 17b). This way they are able to express the idea of stability in an insecure world. The reason is that the bricks are typical index signs and communicators can express meaning with their help.

One of the connotations of brick is stability. Houses are made of bricks, so they convey the idea of shelter for people - protecting them from the unstable and dangerous outside world.

The headline of the bank ad underlines that the savings of bank clients are safe and stable.

The material, from which the billboard is made also supports this idea.

This again proves the semiotic axiom that everything can express meaning.

With its help we can create efficient texts. A typical example in this regard is the billboard described above. It communicates at one and the same time, not only by the text of the ad on it, but also by the materials from which the billboard is made (typical index sign), the idea of stability.

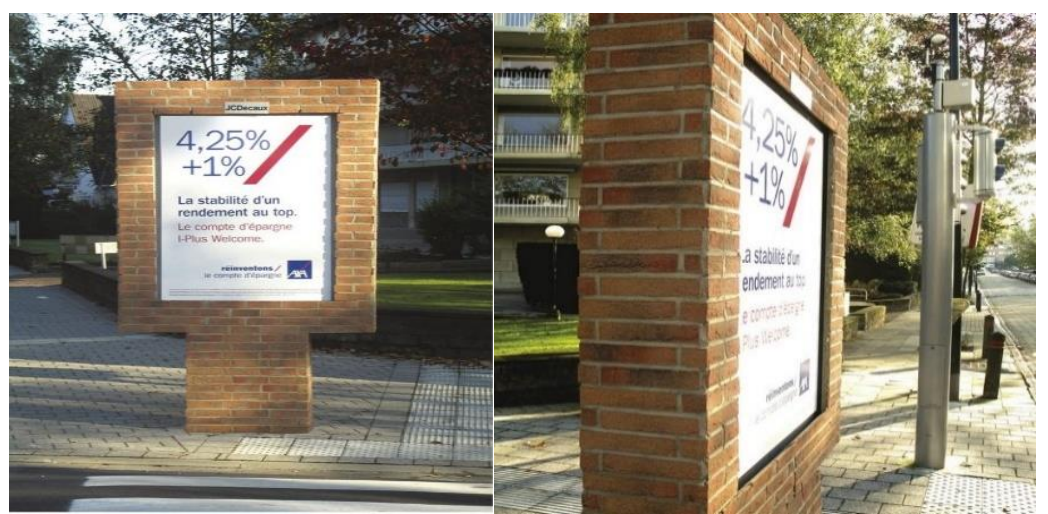

Fig. 17a, 17b. Courtesy

In two other ads (Fig. 18a, 18b) British pensioners are carrying a poster (mounted on a frame) with the following text "If there had been saving plans in funds when I was young, I wouldn't have to work now."

Here are used at least two semiotic concepts as communicative approaches.

The first one is "semantic field". It is the sum of all the signs by which we can express a given notion. The concept of "poverty" can well be illustrated by showing pensioners because they are usually short of money. 
Numerous symbols and iconic signs representing pensioners - words, various images (drawings, pictures, etc.) - can express the concept of poverty. From a semiotic standpoint of view, real, retired people are typical index signs symbolizing the phenomenon of "poverty".

The second concept is "context". This way context (with the help of its meanings) weakens or enhances the meaning of the surrounding text.

The above described ad, showing poor pensioners and having a dramatic headline, shows the effectiveness of fear appeals very well.

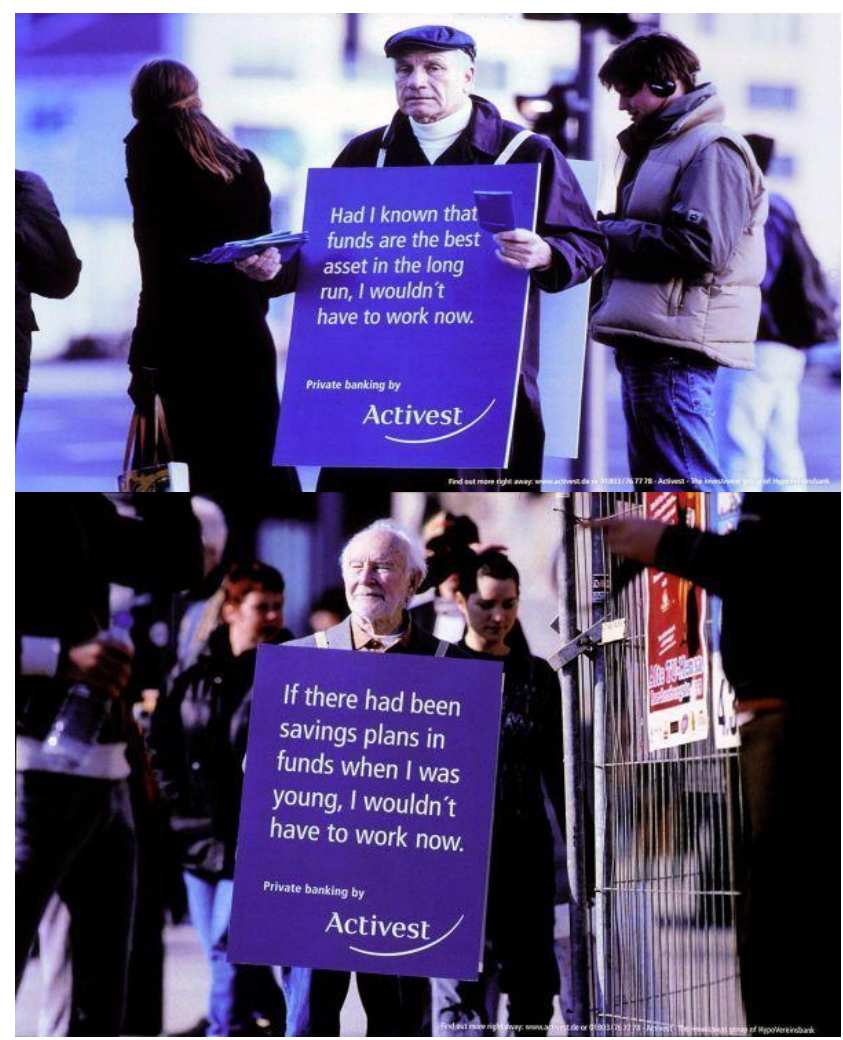

Fig. 18a, 18b

One ad agency created a social installation for a bank which demonstrates people in a difficult situation with a similar semiotic mechanism - erasing the border between the sign (tenor) and its vehicle (medium).

Instead of seeing helpless people in print ads, in commercials or on billboards, we recognize them almost as real persons on the street (Fig. 19). There is nothing new from a semiotic standpoint - the sculptures are usual signs. The same applies to the store window dummies, etc. The setup, on the other hand, is only new with regard to the 3D signs, which are becoming more and more popular with the technological progress (3D printers, etc.). 


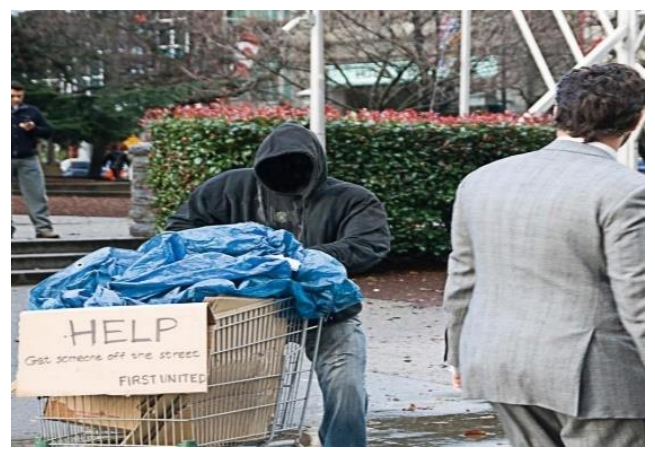

Fig. 19. Courtesy

There are also other marketing communications by which adpersons can express fear appeals, one of them being direct marketing communication (DMC).

DMC means that we do not use mass media - such as newspapers, magazines, TV channels, and so on, but that we communicate directly with the customers - without any middlemen.

The admen who created a direct marketing campaign for financial company (Fig. 20a, 20b, 20c) put broken pots on the sidewalks in order to communicate the urgent need of having insurance. The pots look as if they had fallen from the balconies. In this case, it is the pots that serve as ad vehicles - they are branded with the logo of the insurance company.

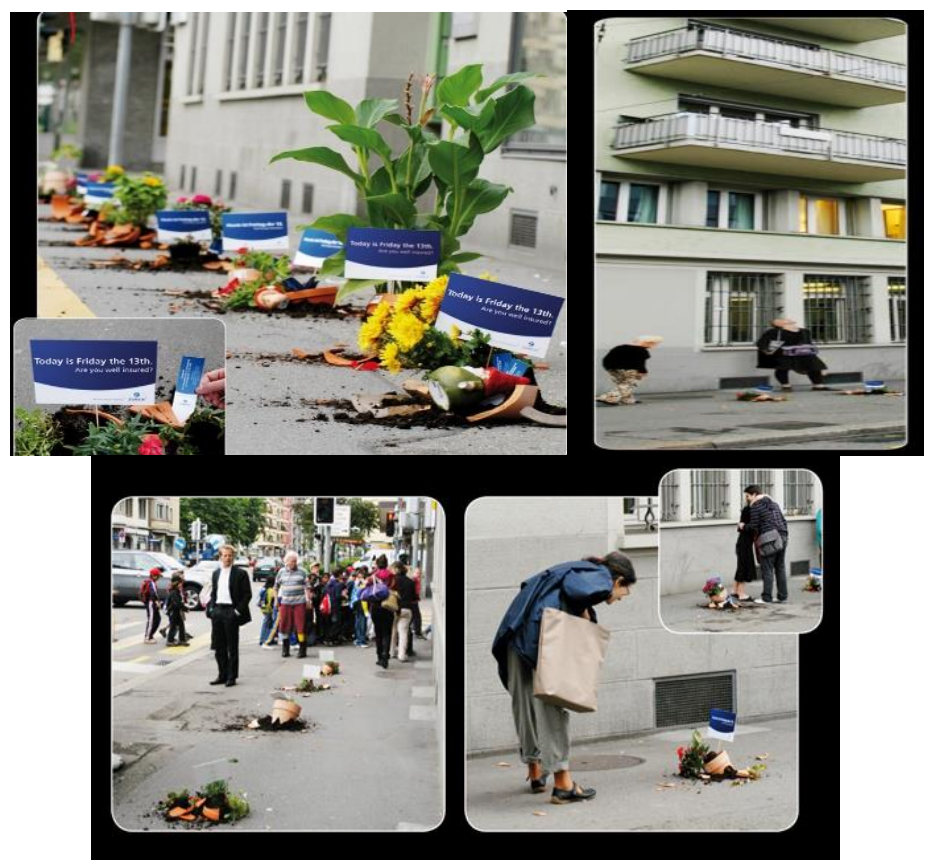

Fig. 20a, 20b, 20c. Courtesy

Also banking services dramatized direct marketing communications (Fig. 21).

To make the windshields of the cars look smashed, the admen used stickers, glued onto the windshields. 
This is an example of communicative approach by index metaphor as well. Verbal messages are replaced by objects - in this case by stickers fixed to a cracked car windshield.

Thus, the admen, in a sophisticated way, convey the idea of danger, and simultaneously they allude to the magic weapon respectively cure to solve the problem (i.e. the necessary insurance that helps the drivers to avoid that risk).

The adpersons also make use of another communicative approach here - this of Ambient.

It is easy for thieves to smash a window and to ravage our precious private space. This way the window is the natural sign-carrier (sign-vehicle) of DMC.

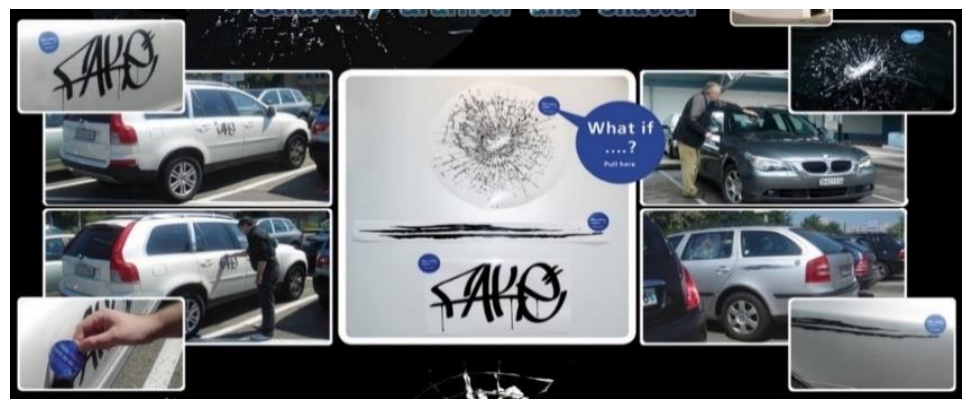

Fig. 21. Courtesy

In the ad shown in Fig. 22 a car is bursting through the façade of Zurich Insurances headquarters. This situation is dramatic - but not tragic because the car is still in a relatively safe position, as only its front part is sticking out of the facade.

This installation symbolizes danger and points to the need to be in a safe position - with the help of insurance, of course. Here the adpersons employ the syntactic concept of "connection" as a communicative approach. Also, the damaged car and the ad headline "Zurich Help Point" constitute a new context which reinforces/enhances the message of the ad. The car is an integral part of the visual image, forming the letter "O" of the word "Point".

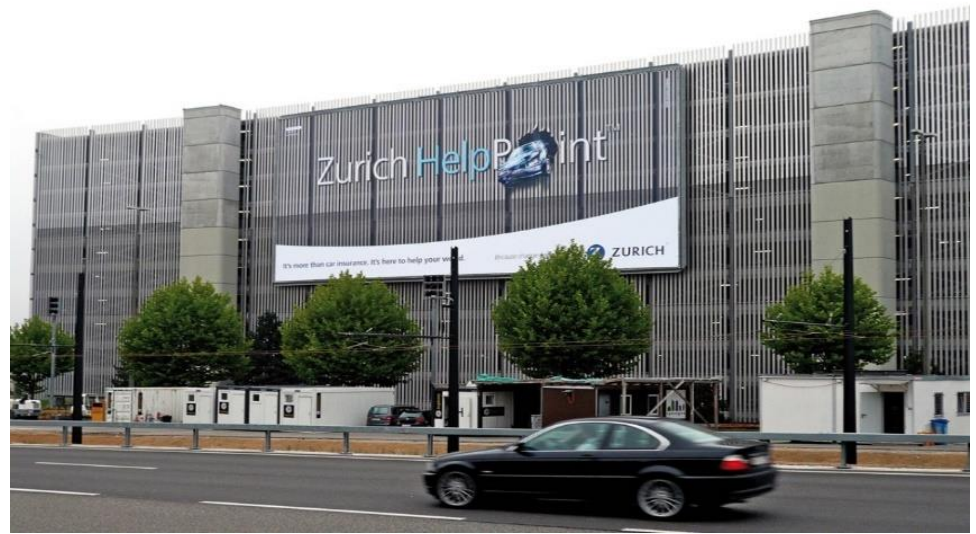

Fig. 22. Courtesy

\section{Fear Appeals in Crisis Situations}

The communicative approaches of signs and ads which show tragic situations are similar to those used when talking about dramatic times. Admen only change the emotional intensity of appeals - from drama to tragedy appeals. 
Strong artistic impact is achieved in two ads for an investment fund (see Fig. 23a, 23b) carrying the headline "Don't be lost in the Weird World of Investments." Both ads make use of the communicative approach of intertextuality. They interpret in their own way two paintings by Salvador Dali:

The Persistence of Memory and Temptation of St. Anthony.
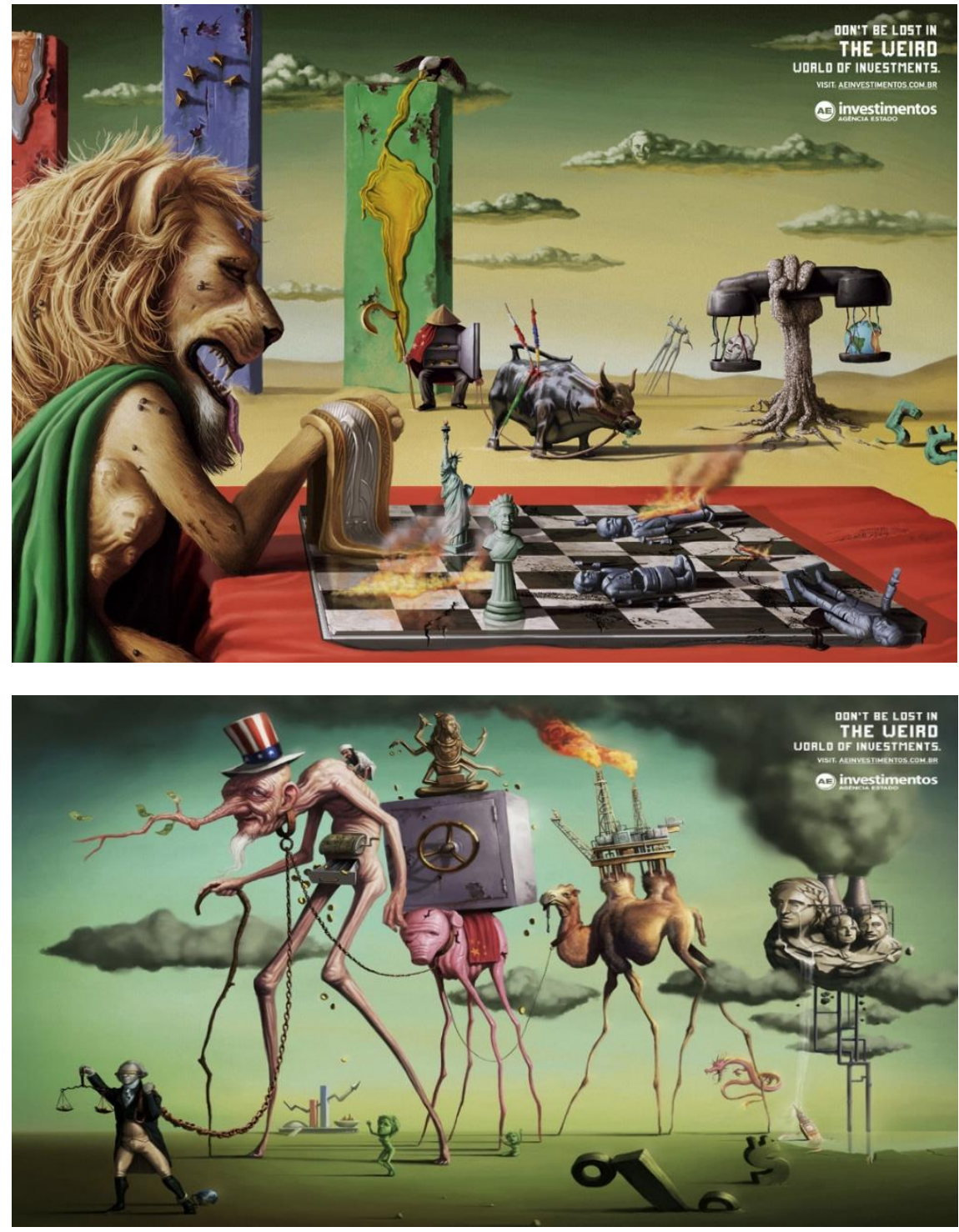

Fig. 23a, 23b. Courtesy

Both the solid and the hard objects depicted in the first ad (Fig. 23a) are melting like vax.

The allusion to Dali's famous clock is quite obvious. The melting euro, made of wax, is in the hand of an old and sick lion, representing the terrible state of the financial world.

All signs in the ad suggest how unstable this currency is. On the chessboard are the English Queen and the Statue of Liberty, and a bit more backwards is the bull - the commonly known Wall Street symbol of prosperous financial markets. 
However, the bull is dying here because it connotes financial disasters in this particular case.

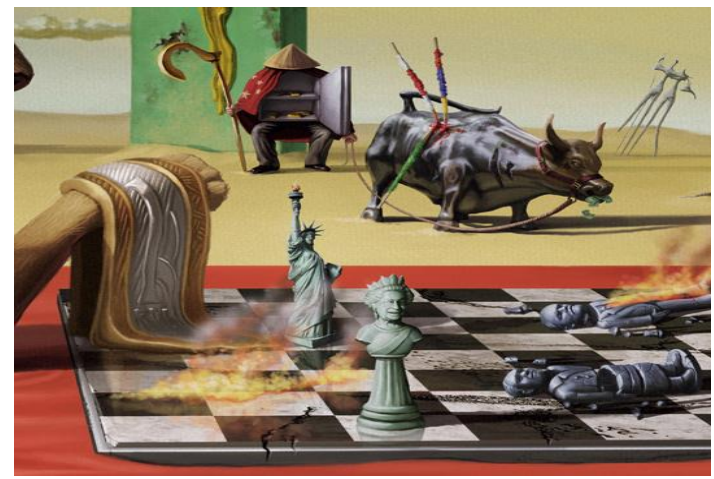

Fig. 23a. Courtesy

There are also a large number of other cross-references in the ad shown in Fig. 23b. Another painting by Salvador Dali "Temptation of St. Anthony" served the admen as a model from which they drew their inspiration.

In this ad there are loans from other works of artists as well. The blind (metaphorically speaking) American dollar (in the shape of one of the US presidents depicted on it) leads the world to peril. This way the ad is related to Peter Brueghel's painting "Blind Leading the Blinds".

The thin-legged horse in Dali's painting is replaced with the caricature of Uncle Sam. Bill Laden rides the horse, and a cash drawer comes out of the horse's abdomen - like in Dali's painting "The Burning Giraffe". All of these iconic signs suggest that the financial world is mad and perverted.

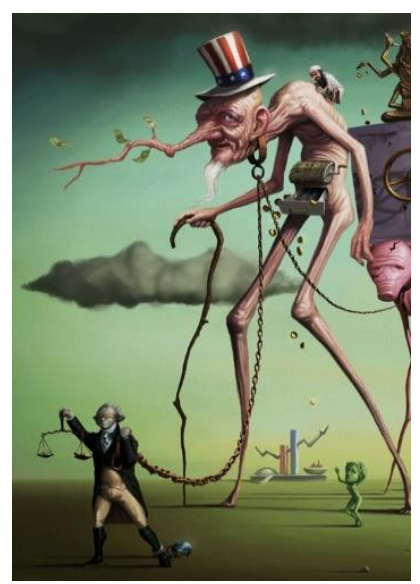

Fig. 23b, 1. Courtesy

\section{The Appeals of Destruction and (Cruel) Death}

Admen create even more sinister ads. Rachel (one of the three insured persons) is shown as dead in an ad for Bradesco Life Insurance (Fig. 24). Here is used verbal (typographic)- 
iconic metonymy. In place of Rachel dead body, the six letters of which her name is composed are lying on the ground.

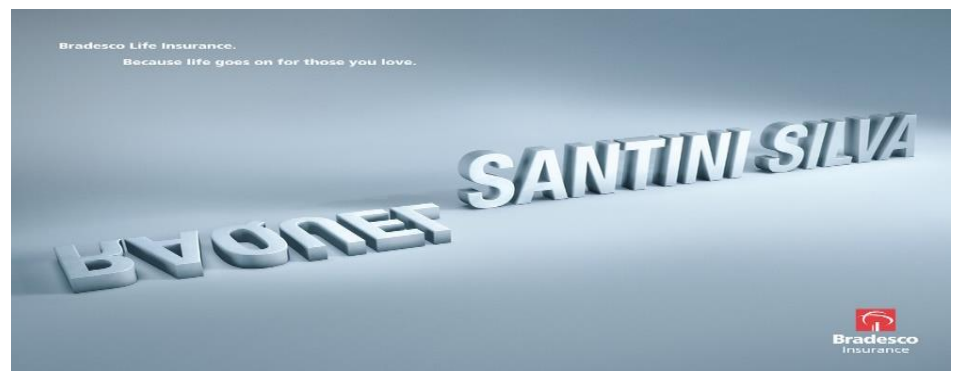

Fig. 24. Courtesy

The terrible scale of possible future ecological catastrophes (horrifying urbanized spaces, countless factory chimneys emitting tons of poisonous gases) is depicted in two ads of a financial newspaper, the "Gazeta del Mercantil". The headline of these ads is "Understand the real value of money” (Fig. 25a, 25b).

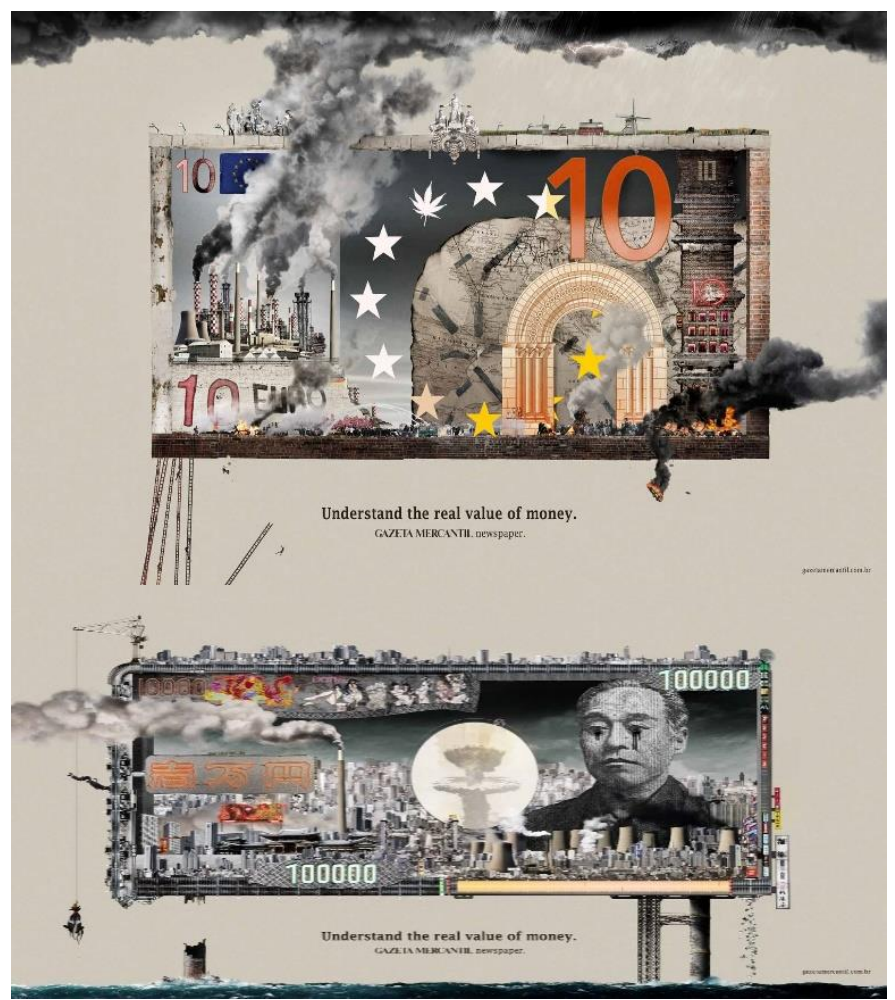

Fig. 25a, 25b

The situation is even more tragic in the third ad of this series (Fig. 25c). Hell is connoted not only with ecological disaster on an unprecedented scale, but also with a humanitarian catastrophe - the destruction of the World Trade Centre that caused the tragic deaths of thousands of people. 
The reason is obvious, according to the ads: All of these tragedies happen because of financial villains - the euro and the Asian currency in the first two ads, and the dollar in the third one.

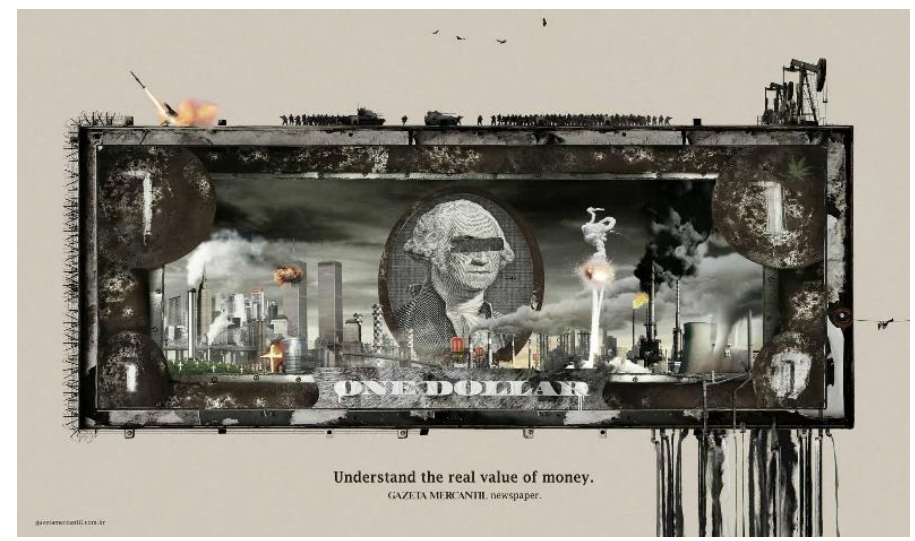

Fig. 25c

In another three banks ads (Fig. 26a, 26b, 26c) the same eschatological appeals are actualized. The world is depicted as flooded by terrifying tsunamis (Fig. 26a), invaded by aliens (Fig. 26b), and, on top of it all, attacked by terrible meteorites and awful dinosaurs at one and the same moment (Fig. 26c).

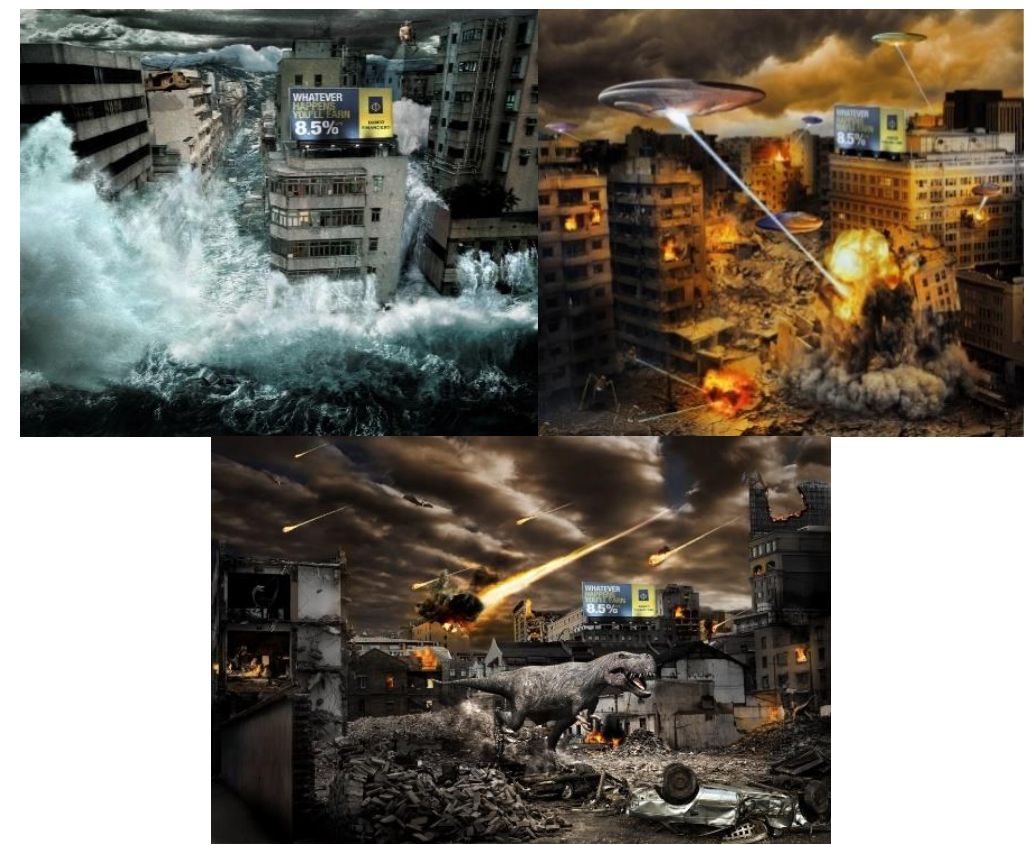

Fig. 26a, 26b, 26c. Courtesy

The admen use these horrors to show how robust their bank is. It is not by accident that the headline of the three ads makes the same claim: "Whatever happens, you earn $8.5 \%$ interest." 
These three ads are good examples of the simultaneous use of two stylistic figures hyperbole and contrast. The banks are very stable on the background of the hyperbolized deadly horrors.

In the following three ads for insurance companies the admen applied three communicative approaches simultaneously (Fig. 27a, 27b, 27c). These communicative approaches are based on one stylistic figure - iconic metaphor - and on two semantic concepts: "iconic redundancy" and "iconic semantic field":

- iconic metaphor - the hair of the three unfortunate men has been replaced by objects that represent all kinds of accidents that might happen to them - catastrophes, terrorist acts, surgical operations, mothers-in- law, etc.

- iconic redundancy: Redundancy is a semantic concept expressing the idea of abundance. Communicators use redundancy as a communicative approach to highlight a given phenomenon with the help of many signs.

- iconic semantic field: An iconic semantic field is the sum of all signs by which communicators can express something. This field is not homogeneous, complete or determined forever. Its volume and structure vary, according to different cultures, different individuals, levels of education, gender, age, religion, lifestyles, etc.

The semantic field of the term "tragedy" involves various types of death and villains, different kinds of wars, diseases, eschatological myths, etc. Several constitutional elements of an eschatological semantic field are made use of in these three ads:

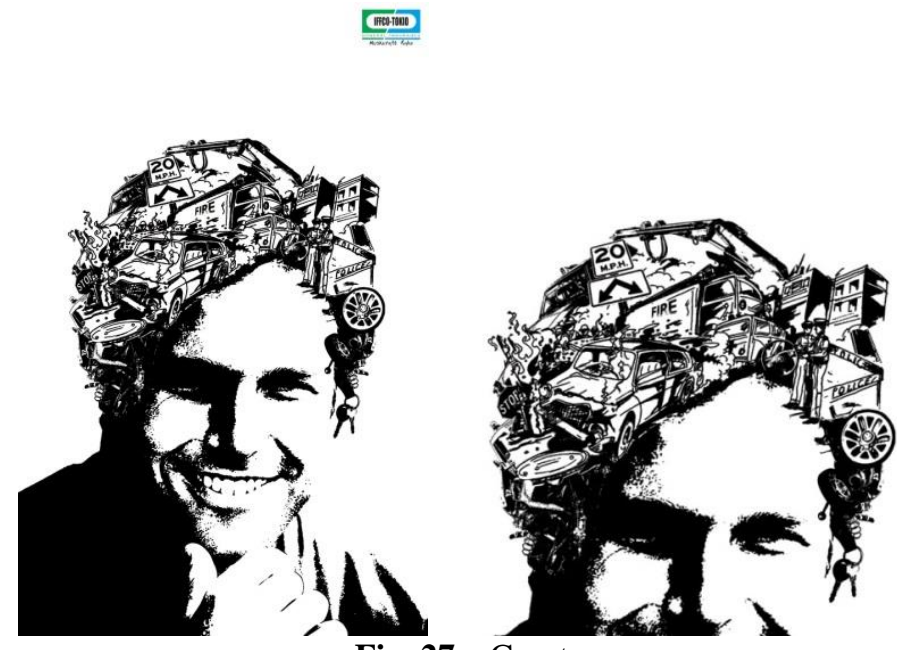

Fig. 27a. Courtesy 

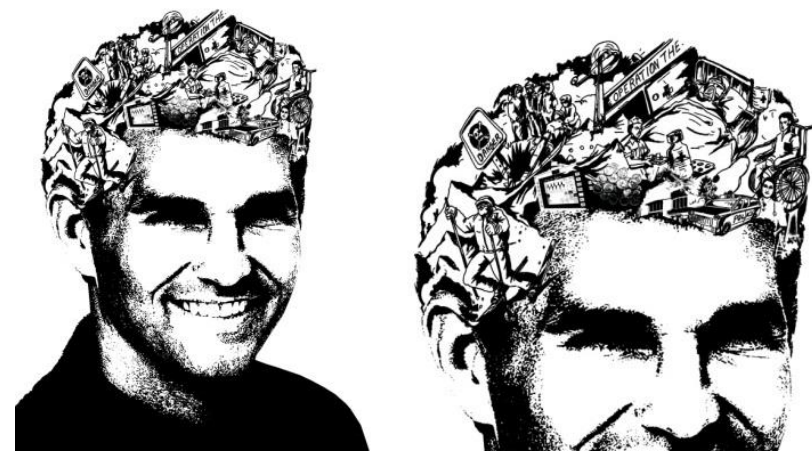

Fig. 27b. Courtesy
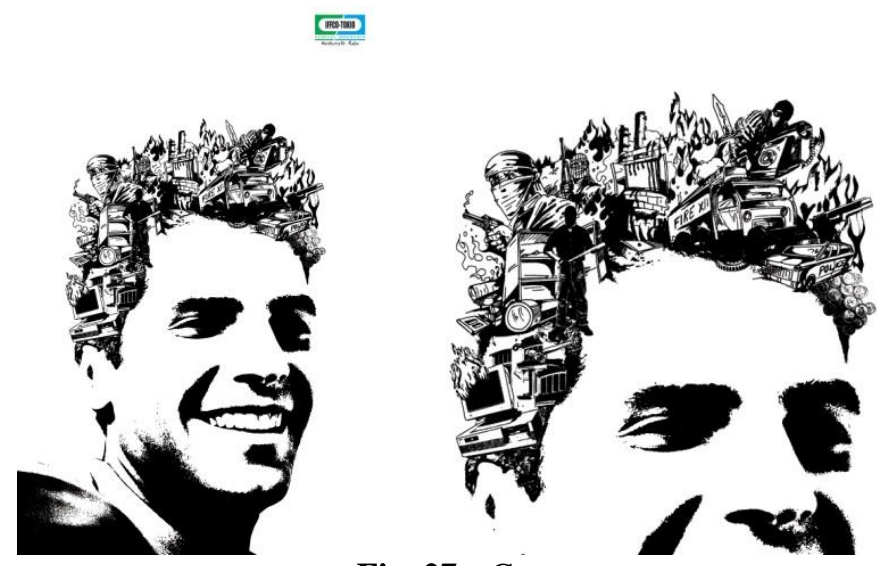

Fig. 27c. Courtesy

\section{ConclusionS}

1. Financial crisis, fear appeals and their dramatic and eschatological interpretations.

The present financial crisis has been existing for quite some time now and our latent, but also our apparent fears, are growing. This is understandable, knowing how important the subconscious is. It is heavily nourished not only by eschatological myths, but also by the cruel social and financial reality we live in.

That is why fear appeals are so frequently used in advertising and in other marketing and mass communications - journalist, social nets, Hollywood, art communications, etc.

This also explains why even corpses can appear in ads - like in a Chinese outdoor for telecommunication services (Fig. 28). It shows - in 3D - the image of the corpse of a person that committed suicide (the person hanged himself). The background of the ad gives the answer - stock market shares have fallen, and the headline states accordingly: "Better to leave our money here than put it on the stock market." 


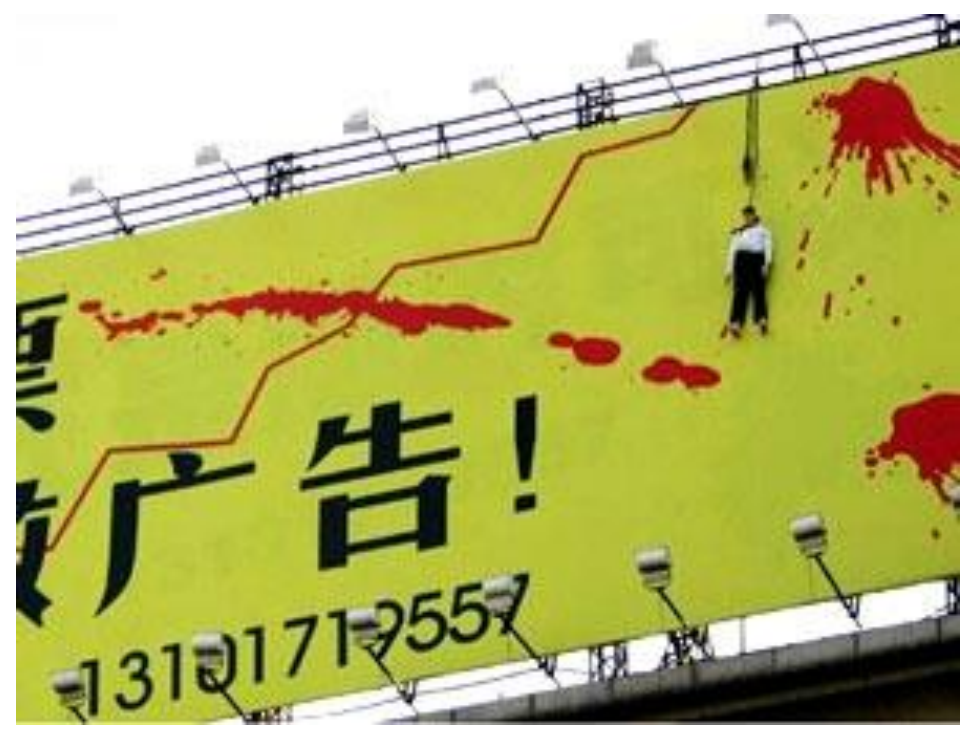

Fig. 27. Courtesy

2. Semiotic concepts as communicative approaches.

Semiotic concepts are not only abstract phenomena, but also effective communicative approaches. The admen can use them in various communications, including advertising. For example, Vodka Absolut has, over a period of 30 years, created and developed efficient advertising and integrated marketing communications campaigns on the basis of numerous iconic metaphors of its bottle.

The semioticians working in marketing and advertising deliberately apply the diverse semiotic concepts as efficient communicative approaches.

Advertising and other marketing communications of some world companies have been developed in such a sophisticated way that they may require new linguistic and semiotic concepts in order to cover the new communicative challenges and dimensions.

\section{REFERENCES}

1. Allen, D. (2002). Myth and Religion in Mircea Eliade. Routledge, New York and London.

2. Allen, G. (2011). Intertextuality. Routledge, Second edition.

3. Cabric, M. (2017). From Corporate Security to Commercial Force. eBook, pp. 145157.

4. Ciro, T. (2013). The Global Financial Crisis: Triggers, Responses and Aftermath. Ashgate Publishing.

5. Clayton, J., Eric Rothstein (Eds.). (1991). Influence and Intertextuality in Literary History. The University of Wisconsin Press.

6. Crawford, H. J., Gary D. G. (2015). Humorous advertising that travels: A review and call for research. Journal of Business Research. Volume 68, Issue 3, March 2015, pp. 569-577.

7. de Mooij, M. (2014). Global Marketing and Advertising: Understanding Cultural Paradoxes. Sage, New York.

8. Fadda, S., Pasquale T. (Eds.) (2013). Financial Crisis, Labour Markets and Institutions. Routledge. 
9. Fennis, B. M., Wolfgang S. (2015). The Psychology of Advertising. Routledge. Second edition.

10. Forest, F. (2016). Psychoanalysis of Advertising. International Journal of Applied Psychoanalytic Studies. Volume 13, Issue 4, December, pp. 338-350.

11. Friedman, J., Kraus, V. (2011. Engineering the Financial Crisis: Systemic Risk and the Failure of Regulation. University of Pennsylvania.

12. Gill, L., E. (2013). Advertising and Psychology. Routledge, Third edition. London \& New York.

13. Haineault, D., Jean-Yves, R. (1993). Unconscious for Sale: Advertising, Psychoanalysis, and the Public. University of Minnesota Press, p. 214.

14. Hartmann, P., Apaolaza-Ibáñez, V. (2010). Beyond savannah: An evolutionary and environmental psychology approach to behavioural effects of nature scenery in green advertising. Journal of Environmental Psychology. Volume 30, Issue 1, March, pp. 119-128.

15. Hastings, G., e Stead, M., Webb, J. (2004). Fear appeals in social marketing: Strategic and ethical reasons for concern. Psychology and Marketing. Volume 21, Issue 11, November, pp. 961-986.

16. Haugtvedt, C. P., Herr, P. Kardes, F. (Eds.). (2012). Handbook of Consumer Psychology. Taylor \& Francis Group, New York and London

17. Heath, R. (2015). Seducing the Subconscious: The Psychology of Emotional Influence in Advertising. Wiley-Blackwell.

18. Lakoff, G., Johnson, M. (1980). Metaphors we Live by. Chicago, The University of Chicago Press.

19. LaTour, M., Pitts, R. (1989). Using Fear Appeals in Advertising for Aids Prevention. Journal of Health Care Marketing; Boone 9. September, p. 5.

20. LaTour, M., Shaker, Z. (1989). Fear Appeals as Advertising Strategy: Should They Be Used? The Journal of Consumer Marketing; Santa Barbara 6.2, Spring, p. 61.

21. Lewis, I., Watson, B., Tay, R., White, K. M. (2007). The role of fear appeals in improving driver safety: A review of the effectiveness of fear-arousing (threat) appeals in road safety advertising. International Journal of Behavioural Consultation and Therapy, Vol. 3(2), pp. 203-222.

22. Meletinsky, E. M. (2014). The Poetics of Myth. Routledge, New York and London.

23. Mueller, Barbara. (2011). Dynamics of International Advertising: Theoretical and Practical Perspectives. Peter Lang, New York.

24. Oldani, C., Kirton, J.J., Savona, P. (Eds.) (2013). Global Financial Crisis: Global Impact and Solutions. Routledge.

25. Oswald, L. R. (2010) Marketing hedonics: Toward psychoanalysis of advertising response. Journal of Marketing Communications, Volume 16, Issue 3, pp. 107-131.

26. Packard, V. (1964). The Hidden Persuaders. New York, Pocket Books.

27. Rakowski, N. (2008). Maslow's hierarchy of needs model - the difference of the Chinese and the Western pyramid on the example of purchasing luxurious products. Essay.

28. Rossolatos, G. (2013). Rhetorical Transformations in Multimodal Advertising Texts: From General to Local Degree Zero. Hermes - Journal of Language and Communication in Business, № 50, pp. 97-118.

29. Rossolatos, G. (2014). Conducting Multimodal Rhetorical Analysis of TV Ads with Atlas.ti 7. Mouton de Gruyter, 3(1); pp. 51-84.

30. Seeley, E. (1992). Human needs and consumer economics: the implications of Maslow's theory of motivation for consumer expenditure patterns. The Journal of Socio-Economics. Volume 21, Issue 4, autumn, pp. 303-324. 
31. Witte, K., Mike, A. (2000). A Meta-Analysis of Fear Appeals: Implications for Effective Public Health Campaigns. Health Education \& Behaviour. Volume 27 issue 5, pp. 591-615.

32. Worton Michael, Judith Still. (Eds.) (1991). Intertextuality: Theories and Practices. Manchester University Press.

33. Zantides, E. (2016). Visual Metaphors in Communication: Intertextual Semiosis and Deja Vu in Print Advertising. Romanian Journal of Communication and Public Relations. vol. 18, no. 3 (39), December, pp. 65-74.

\section{Article history:}

Received 7 May 2018

Accepted 15 June 2018 